\title{
Adiponectin regulates glycogen metabolism at the human fetal-maternal interface
}

\author{
Fabien Duval', Esther Dos Santos1,2, Benoît Maury1, Valérie Serazin1,2, Khadija Fathallah33, François Vialard1,3 and \\ Marie-Noëlle Dieudonné
}

${ }^{1}$ GIG - EA 7404, Université de Versailles-Saint Quentin en Yvelines - Université Paris Saclay, Unité de Formation et de Recherche des Sciences de la Santé Simone Veil, Montigny-le-Bretonneux, France

${ }^{2}$ Service de Biologie Médicale, Centre Hospitalier de Poissy-Saint Germain, Poissy, France

3Département de Biologie de la Reproduction, Cytogénétique, Gynécologie et Obstétrique, Centre Hospitalier de Poissy-Saint Germain, Poissy, France

Correspondence should be addressed to M-N Dieudonné: marie-noelle.dieudonne@uvsq.fr

\begin{abstract}
Throughout the entire first trimester of pregnancy, fetal growth is sustained by endometrial secretions, i.e. histiotrophic nutrition. Endometrial stromal cells (EnSCs) accumulate and secrete a variety of nutritive molecules that are absorbed by trophoblastic cells and transmitted to the fetus. Glycogen appears to have a critical role in the early stages of fetal development, since infertile women have low endometrial glycogen levels. However, the molecular mechanisms underlying glycogen metabolism and trafficking at the fetal-maternal interface have not yet been characterized. Among the various factors acting at the fetal-maternal interface, we focused on adiponectin - an adipocyte-secreted cytokine involved in the control of carbohydrate and lipid homeostasis. Our results clearly demonstrated that adiponectin controls glycogen metabolism in EnSCs by (i) increasing glucose transporter 1 expression, (ii) inhibiting glucose catabolism via a decrease in lactate and ATP productions, (iii) increasing glycogen synthesis, (iv) promoting glycogen accumulation via phosphoinositide-3 kinase activation and (v) enhancing glycogen secretion. Furthermore, our results revealed that adiponectin significantly limits glycogen endocytosis by human villous trophoblasts. Lastly, we demonstrated that once glycogen has been endocytosed into placental cells, it is degraded into glucose molecules in lysosomes. Taken as a whole, the present results demonstrate that adiponectin exerts a dual role at the fetal-maternal interface by promoting glycogen synthesis in the endometrium and conversely reducing trophoblastic glycogen uptake. We conclude that adiponectin may be involved in feeding the conceptus during the first trimester of pregnancy by controlling glycogen metabolism in both the uterus and the placenta.
\end{abstract}

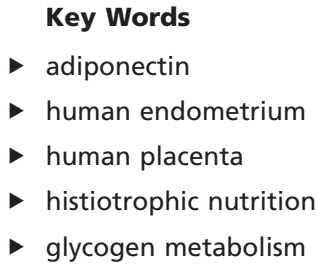

Journal of Molecular Endocrinology (2018) 61, 139-152

\section{Introduction}

Efficient nutrient exchange between the mother and the fetus is essential for a successful pregnancy and requires adequate placental development. The human placenta is a transient organ composed of embryo-derived cells called trophoblasts. The syncytiotrophoblast (ST) is a specialized multinuclear syncytium located on the outer layer of placental villi. It is directly derived from villous trophoblast (VT) fusion. The ST is crucial for nutrient and 
gas exchange and displays an intense endocrine activity (Lunghi et al. 2007). During the early stages of in utero development, the embryo is nourished via a histiotrophic pathway in which nutritive uterine secretions (derived from endometrial glands) are endocytosed by VT cells (Burton et al. 2002, 2007, Hempstock et al. 2004). More precisely, nutrients (lipids, proteins and glycogen) accumulate specifically in endometrial stromal cells (EnSCs), which differentiated into decidual cells in response to ovarian hormones 17 $\beta$-estradiol (E2) and progesterone (P4) (Irwin et al. 1989, Hempstock et al. 2004). Throughout decidualization, endometrial glycogen production increases and peaks during the secretory phase corresponding to the implantation window (Mimori et al. 1981). Moreover, it was reported that endometrium from infertile women present low endometrial glycogen levels suggesting that endometrial glycogen production is critical for embryo implantation (Maeyama et al. 1977). While the enzymes involved in endometrial glycogenesis are well established i.e. glycogen synthase

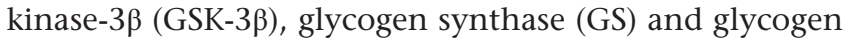
phosphorylase (GP) (Salameh et al. 2006, Rose et al. 2011), little is known concerning glycogen trafficking from the endometrium to the placenta. Only three studies suggest an exocytosis/endocytosis glycogen transport at the fetalmaternal interface, although the details of glycogen use following endocytosis by the ST have not (to the best of our knowledge) been characterized (Burton et al. 2002, 2011, Jones et al. 2015). Glycogen vesicular transport has been demonstrated in several cell types. More precisely, after endocytosis, vesicular glycogen is carried toward lysosomes in order to be hydrolyzed into glucose. This process is called glycophagy (Kaur \& Debnath 2015). It can be hypothesized that endometrial glycogen follows this pathway and thus provides placental cells and/or the fetus with glucose.

Adiponectin is a $30 \mathrm{kDa}$ protein that is described as an insulin-sensitizing hormone (Yamauchi et al. 2001). More precisely, adiponectin stimulates glucose assimilation and fatty-acid transport in muscle cells (Ceddia et al. 2005, Qiao et al. 2012). Moreover, adiponectin promotes the catabolism of carbohydrates and lipids by enhancing the glycolysis and $\beta$-oxidation pathways (Yamauchi et al. 2002, Combs \& Marliss 2014). These effects seem to be mediated by the activation of the AMP-activated protein kinase (AMPK) pathway (Yamauchi et al. 2002). Furthermore, adiponectin reportedly exerts anti-inflammatory, antiangiogenic, anti-atherosclerotic, anti-proliferative and pro-apoptotic roles in various cell types (Yamauchi et al. 2003a, Dieudonne et al. 2006, Duval et al. 2016). These effects are mediated by a variety of pathways, including the phosphoinositide-3 kinase (PI3K), the protein kinase $\mathrm{A}$ and the mitogen-activated protein kinase pathways (Ouchi et al. 2000, Yamauchi et al. 2003b, Benaitreau et al . 2009).

Some research results suggest that adiponectin is a key actor of the fetal-maternal interface dialog. It has been reported that the adiponectin receptors, ADIPOR1 and ADIPOR2 (Yamauchi et al. 2003b), are expressed in human endometrium and placenta (Takemura et al. 2006, Benaitreau et al. 2009). Experiments performed in our laboratory clearly demonstrated that adiponectin favors the development of a normal placenta with differentiative and anchoring abilities (Benaitreau et al. 2010a,b). Surprisingly, using human and murine models, we and others have shown that adiponectin downregulates glucose and amino acid transporters in placenta (Caminos et al. 2005, Jones et al. 2010, Rosario et al. 2012, Duval et al. 2016). We also demonstrated that adiponectin downregulates mitochondrial biogenesis but increases energy production in human VTs (Duval et al. 2016). Furthermore, the adiponectin system has a critical role in uterine receptivity. Indeed, endometrial ADIPOR expression is abnormally low in infertile women and is at its highest during the implantation window in fertile women (Takemura et al. 2006, Santos et al. 2012). Furthermore, we recently observed that adiponectin exerts anti-differentiative and anti-invasive effects in human EnSCs (Duval et al. 2017).

Considering the importance of adiponectin in the control of glucose metabolism, we aimed to study the in vitro effect of human recombinant adiponectin on glycogen synthesis and trafficking at the human fetalmaternal interface. To this end, we studied (i) glucose metabolism leading to glycogen accumulation in human EnSCs and (ii) glycogen uptake and use in human VTs. Our results contribute to a better understanding of histiotrophic nutrition in general and adiponectin involvement in this pathway in particular.

\section{Materials and methods}

\section{Materials}

Dulbecco's Modified Eagle's Medium and Ham F-12 Nutrient Mix (DMEM/F12), progesterone, 17 $\beta$-estradiol, penicillin, streptomycin, DNase type I, EDTA, leupeptin, aprotinin, 4-(2-aminoethyl)-benzene-sulfonyl fluoride (AEBSF), sodium fluoride (NaF), Compound C, LY294002 and bovine serum albumin (BSA) were purchased 
from Sigma Chemical Co. Fetal calf serum (FCS) was purchased from Gibco (Invitrogen). Recombinant human adiponectin was provided by R\&D Systems Europe Ltd. Superscript III RNase H-RT and primers were from Invitrogen, and RNase inhibitor was obtained from AMRESCO (Solon, OH, USA). Nucleospin RNA II kit was obtained from Machery-Nagel (Düren, Germany). Trypsin was provided by Difco Laboratories (Detroit, MI, USA). Collagenase A was obtained from Boehringer (Mannheim, Germany). The suppliers of the various antibodies used in our experiments are described in the corresponding sections below.

\section{Study population and tissue collection}

Endometrial biopsies were programmed during a monitored natural cycle, 7-9 days after the ovulation surge (LH surge), during the hypothetical implantation window. Patients with a low endometrial volume $(<2 \mathrm{~cm})$, submucous fibroma or polyps were excluded. Thirtytwo normally cycling women (aged 25-41) undergoing endometrial biopsy for fertility evaluation were recruited into the study. First-trimester human placental tissues (4- to 10-week gestational age) were obtained from 12 healthy pregnant women (aged 18-42) undergoing legal abortions. The present study was approved by the local investigational review board (Comité Consultatif de Protection des Personnes dans la Recherche Médicale, approval reference protocol 01-78). All participants provided their written informed consent prior to tissue sampling.

\section{EnSC culture}

Human EnSCs were isolated and cultured as previously described (Duval et al. 2017). Isolated EnSCs were characterized by positive staining for vimentin (95\% stained positive) and negative staining for pancytokeratin (95\% stained negative). Isolated EnSCs are able to differentiate in vitro, when incubated with E2 $\left(10^{-8} \mathrm{M}\right)$ and $\mathrm{P} 4\left(10^{-6} \mathrm{M}\right)$, as shown by the progressive rise in prolactin secretion during the cell culture period (Duval et al. 2017). After isolation, EnSCs were seeded in 12-well culture plates $\left(1.5 \times 10^{4}\right.$ cells per well) and cultured in phenol-red-free DMEM/F12 medium supplemented with streptomycin $(10 \mu \mathrm{g} / \mathrm{mL})$, penicillin $(100 \mathrm{U} / \mathrm{mL})$ and FCS $(10 \%)$ at $37^{\circ} \mathrm{C}$ in a $5 \% \mathrm{CO}_{2}$ and $95 \%$ air atmosphere for $48 \mathrm{~h}$. EnSCs were then cultured in differentiation medium (DMEM/F12 with E2 $\left(10^{-8} \mathrm{M}\right)$, P4 $\left(10^{-6} \mathrm{M}\right)$, charcoalstripped FCS (2\%), penicillin $(10 \mu \mathrm{g} / \mathrm{mL})$ and streptomycin
$(100 \mathrm{U} / \mathrm{mL}))$. This differentiation medium was supplemented or not with increasing doses of human recombinant adiponectin (from $25 \mathrm{ng} / \mathrm{mL}$ to $1000 \mathrm{ng} / \mathrm{mL}$ ) for 15 days - the time required to obtain fully differentiated decidual cells (Duval et al. 2017). The culture medium was renewed every $48 \mathrm{~h}$.

\section{Reverse transcription - quantitative polymerase chain reaction}

EnSCs were seeded in 12 -well culture plates $\left(3.5 \times 10^{5}\right.$ cells per well). After 3, 8 or 15 days of differentiation (D3, D8, D15), total RNA $(0.1 \mu \mathrm{g})$ from EnSCs was extracted and reverse-transcribed, as previously described (MachinalQuélin et al. 2002). Quantitative PCR was performed using the C1000 Thermal Cycler (CFX96 real-time system; BioRad, Hercules) and the primers sets indicated in Table 1. Exon-spanning primers were used to avoid non-specific amplification. RNA samples were treated with DNAse to avoid non-specific amplification. The amplification specificity was also determined by measuring the melting temperature $(\mathrm{Tm})$ of each primer. The second derivative maximum method was used to automatically determine the crossing point (Cp) for individual samples. The three reference genes (ribosomal protein L13A (RPL13A), TATA-binding protein $(T B P)$ and $\beta 2$-microglobulin $(B 2 M)$ ) were chosen as previously described (Benaitreau et al. 2009). For each sample, the concentration ratios (target/three reference mRNA) were calculated using CFX Manager (version 3.0, BioRad). The data were expressed as percentages of the control situation. Calibration curves were log-linear over the quantification range, with correlation coefficients $\left(r^{2}\right)>0.99$ and efficiencies ranging from 1.8 to 2 . The intra-assay variability of duplicate crossing point values never exceeded 0.2 cycles and the inter-assay variability (coefficient of variation) ranged from 1.9 to $4.1 \%$ for $8-10$ runs of each transcript.

\section{Immunoblotting}

EnSCs were seeded onto six-well culture plates $\left(2.0 \times 10^{6}\right.$ cells/well $)$ and lysed on ice in buffer containing Tris $(50 \mathrm{mM}), \quad \mathrm{NaCl} \quad(120 \mathrm{mM})$, EDTA (1 mM), Nonidet-P40 (1\%), deoxycholate (0.1\%), SDS $(0.1 \%)$, sodium vanadate $(1 \mathrm{mM}), \beta$-glycerophosphate (30 mM), aprotinin $(5 \mu \mathrm{g} / \mathrm{mL})$, leupeptin $(12.5 \mu \mathrm{g} /$ $\mathrm{mL}), \operatorname{AEBSF}(100 \mu \mathrm{g} / \mathrm{mL})$ and sodium fluoride $(10 \mathrm{mM})$. Twenty micrograms of proteins were resolved by SDSPAGE (4-20\% acrylamide) and transferred for $150 \mathrm{~min}$ 
Table 1 Primers used for RT-PCR.

\begin{tabular}{|c|c|c|c|}
\hline \multirow[b]{2}{*}{ Primers } & \multicolumn{2}{|c|}{ Sequence } & \multirow[b]{2}{*}{ PCR product $(\mathrm{bp})$} \\
\hline & Sense & Antisense & \\
\hline GLUT1 & $5^{\prime}$ TGA GCA TCG TGG GCA TCT TT 3' & 3' AAG CTA CTC TAG CGA AGG CC 5' & 298 \\
\hline GLUT3 & 5' CAG GCA CAC GGT GCA GAT AG 3' & $3^{\prime}$ CCA CGC AGA TGG GAA CCT TA 5' & 67 \\
\hline GS & 5' AGG CCT TTC CAG AGC ACT TC 3' & $3^{\prime}$ TGG TCT CAC TCC TGC TCC TC 5' & 140 \\
\hline$G P$ & 5' GCA CGC AGC AGC ACT ACT AT 3' & 3' ATA CCC TGC CTG CGA TGT CT 5' & 84 \\
\hline$T B P$ & $5^{\prime}$ TGC ACA GGA GCC AAG AGT GAA 3' & $3^{\prime}$ CAC ATC ACA GCT CCC CAC CA 5' & 132 \\
\hline$B 2 M$ & 5' TGC TGT CTC CAT GTT TGA TGT ATC T 3' & 3' TCT CTG CTC CCC ACC TCT AAG T 5' & 86 \\
\hline RPL13A & 5' CCT GGA GGA GAA GAG GAA AGA GA 3' & 3' TTG AGG ACC TCT GTG TAT TTG TCA A 5' & 125 \\
\hline
\end{tabular}

onto nitrocellulose membranes using a wet transfer method. After transfer, membranes were incubated overnight with the primary antibodies described in Table 2. After washing, the membranes were incubated with peroxidase-coupled secondary antibody for $1 \mathrm{~h}$ at room temperature. The blots were developed using the SuperSignal West Pico Chemiluminescent Substrate (ThermoFisher Scientist Inc.). We used $\beta$-actin as the loading control, in order to normalize our results.

\section{Remaining glucose in cell supernatant}

We considered that low glucose concentrations in cell culture medium corresponded to high glucose uptake by EnSCs. Therefore, we have measured remaining glucose in cell supernatant after 3,8 and 15 days of differentiation (D3, D8 and D15), using an automated enzyme assay (Roche). Glucose levels were normalized per microgram of total proteins, measured using Bradford method, with BSA as the standard.

\section{Lactate production}

Lactate release into the culture medium by EnSCs was measured using an automated enzyme assay (Roche) after 15 days of cell culture, as previously described (Poidatz et al. 2015, Duval et al. 2016). The level was normalized per microgram of total proteins as described earlier.

\section{ATP production}

EnSCs were seeded onto 12-well culture plates $\left(3.5 \times 10^{5}\right.$ cells per well) and lysed on ice in ATP assay buffer. After sonication, cell lysates were centrifuged for $2 \mathrm{~min}$ at $15,000 \mathrm{~g}$. Cellular ATP production was measured using a dedicated assay kit (ab83355, Abcam), as previously described (Poidatz et al. 2015, Duval et al. 2016). A standard curve is performed for each experiment. According to the fluorometric method, results were analyzed with an Infinite M200 microplate reader at $\lambda_{\mathrm{EX}}=540 \mathrm{~nm} / \lambda_{\mathrm{EM}}=590 \mathrm{~nm}$ (Tecan, San Jose, CA, USA) and normalized per microgram of total proteins as described earlier.

\section{Glycogen accumulation}

EnSCs were seeded in 12-well culture plates $\left(3.5 \times 10^{5}\right.$ cells per well). Supernatants were collected in order to measure the extracellular glycogen secretion. In parallel, cells were homogenized in water and boiled $5 \mathrm{~min}$ at $100^{\circ} \mathrm{C}$ to inactivate enzymes. Cell lysates were centrifuged for $5 \mathrm{~min}$ at $13,000 \mathrm{~g}$. Intracellular and extracellular glycogen accumulation were measured using a dedicated assay kit (MAK016, Sigma) (Salker et al. 2017). A standard curve is performed for each experiment. According to the manufacturer's instructions, results were analyzed with an Infinite M200 microplate reader at $\lambda_{\mathrm{EX}}=535 \mathrm{~nm} / \lambda_{\mathrm{EM}}=587 \mathrm{~nm}$ (Tecan) and normalized per microgram of total proteins as described earlier.

Table 2 Primary antibodies used for immunoblotting.

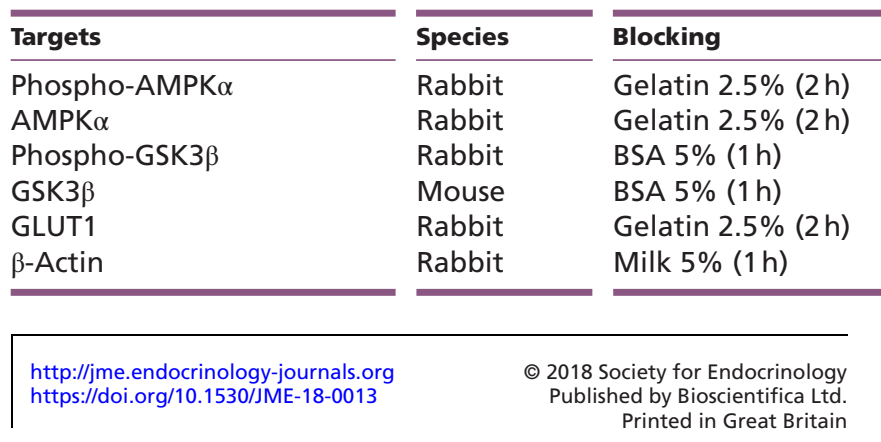

\begin{tabular}{lll}
\hline \multicolumn{1}{c}{ Dilution } & Incubation \\
\cline { 1 - 1 } $1: 700$ & Room temperature \\
$1: 1000$ & Room temperature \\
$1: 1000$ & $+4^{\circ} \mathrm{C}$ \\
$1: 500$ & $+4^{\circ} \mathrm{C}$ \\
$1: 1250$ & Room temperature \\
$1: 500$ & $+4^{\circ} \mathrm{C}$ \\
\hline
\end{tabular}

\begin{tabular}{l} 
Supplier \\
\hline Cell Signaling \\
Cell Signaling \\
Cell Signaling \\
Cell Signaling \\
Abcam \\
Sigma Aldrich
\end{tabular}
Printed in Great Britain 


\section{VT culture}

Human VTs were prepared from tips of placental villi, as previously described (Benaitreau et al. 2010b). Placental villi were incubated five times in HBSS containing trypsin (0.125\%), $\mathrm{MgSO}_{4}(4.2 \mathrm{mM})$, Hepes $(25 \mathrm{mM})$, DNAse type IV $(50 \mathrm{U} / \mathrm{mL})$ at $37^{\circ} \mathrm{C}$ without agitation. Then, villi were washed several times in warm HBSS. The supernatant containing VTs was collected after tissue sedimentation and centrifuged at $200 \boldsymbol{g}$ for $10 \mathrm{~min}$. Then, VTs were filtered through $40 \mu \mathrm{m}$ nylon screen. The cell suspension was layered over a discontinuous Percoll gradient and centrifuged for $25 \mathrm{~min}$ at $1000 \mathrm{~g}$. The layer corresponding to $40-45 \%$ and $50-55 \%$ containing VTs was washed in DMEM/F12 supplemented with FCS $(10 \%)$, penicillin $(10 \mu \mathrm{g} / \mathrm{mL})$ and streptomycin $(100 \mathrm{U} / \mathrm{mL})$. VTs were seeded in 12-well culture plates $\left(1.5 \times 10^{6}\right.$ cells per well) and cultured in phenol-red-free DMEM/F12 medium supplemented with FCS (10\%), streptomycin $(10 \mu \mathrm{g} / \mathrm{mL})$ and penicillin $(100 \mathrm{U} / \mathrm{mL})$ at $37^{\circ} \mathrm{C}$ under $5 \% \mathrm{CO}_{2}$ and $95 \%$ air atmosphere for $24 \mathrm{~h}$. Isolated VTs were characterized by positive staining for cytokeratin-7 (95\% stained positive) and the formation of a syncytium. Moreover, cell preparation was not significantly contaminated by the other major placental cell type (extravillous trophoblasts) because the latter require an artificial matrix for growth in vitro (Tarrade et al. 2001). Concomitantly, we studied syncytialization of VTs by measuring hCG production. VTs are able to fuse spontaneously after $48-72 \mathrm{~h}$ of culture in vitro, as shown the rise in hCG secretion during the cell culture period (Benaitreau et al. 2010b, Poidatz et al. 2014, Duval et al. 2016).

\section{Endometrial glycogen transport from EnSCs to VTs}

VTs were seeded in a 12 -well culture plate $\left(1.5 \times 10^{6}\right.$ cells per well) and cultured in a phenol-red free DMEM/F12 medium supplemented with streptomycin $(10 \mu \mathrm{g} / \mathrm{mL})$, penicillin $(100 \mathrm{U} / \mathrm{mL})$ and FCS $(10 \%)$ at $37^{\circ} \mathrm{C}$ in a $5 \%$ $\mathrm{CO}_{2}$ and $95 \%$ air atmosphere, for $24 \mathrm{~h}$. On the next day, VTs were treated with conditioned medium (CM) from 15-day decidualized EnSCs treated or not with human recombinant adiponectin $(25 \mathrm{ng} / \mathrm{mL}$ or $250 \mathrm{ng} / \mathrm{mL})$. Media from non-decidualized EnSCs were used as controls. After $48 \mathrm{~h}$, glycogen accumulation in placental cells was assayed, as described earlier. The VTs were cultured for a total of $72 \mathrm{~h}$ - the time needed to obtain a functional ST (Benaitreau et al. 2010b, Poidatz et al. 2015, Duval et al. 2016).
Flow cytometry analysis of FITC-dextran absorption by VTs

Dextran is a polysaccharide, with a similar structure to glycogen. More precisely, dextran as well as glycogen present $\alpha(1,4)$ and $\alpha(1,6)$ bounds. Thus, it has been suggested that dextran can be used as a glycogen analog for in vitro and in vivo studies (Simionescu et al. 1972, Takikita et al. 2009). In this context, FITC-dextran was used as a fluorescent glycogen analog in this study. VTs were seeded in 12 -well culture plates $\left(1.5 \times 10^{6}\right.$ cells per well) and cultured in a phenol-red free DMEM/F12 medium supplemented with streptomycin $(10 \mu \mathrm{g} / \mathrm{mL})$, penicillin $(100 \mathrm{U} / \mathrm{mL})$ and FCS $(10 \%)$ at $37^{\circ} \mathrm{C}$ in a $5 \% \mathrm{CO}_{2}$ and $95 \%$ air atmosphere for $24 \mathrm{~h}$. Next, VTs were cultured in DMEM/F12 medium and FCS (1\%) supplemented or not with human recombinant adiponectin $(25 \mathrm{ng} / \mathrm{mL}$ or $250 \mathrm{ng} / \mathrm{mL})$ for $48 \mathrm{~h}$. Next, cells were stained with FITC-dextran for $2 \mathrm{~h}$ at $37^{\circ} \mathrm{C}$. Flow cytometry analysis was performed on LSR Fortessa flow cytometer (BD Biosciences, San Jose, CA, USA). Overall, 100,000 events per conditions were acquired based at first on FSC/SSC distribution and secondly on mean FITC fluorescence intensity. First cell gating based on FSC/SSC did remove cell debris but did not allow us to distinct cytotrophoblasts and ST of variable sizes. Cells not exposed to FITC-dextran were used as 'unstained' cells and negative control.

\section{Confocal microscopy analysis of fluorescein isothiocyanate (FITC)-dextran absorption by VTs}

VTs were seeded in a Labtech culture device $\left(1.0 \times 10^{5}\right.$ cells per well) and cultured in a phenol red-free DMEM/F12 medium supplemented with streptomycin $(10 \mu \mathrm{g} / \mathrm{mL})$, penicillin $(100 \mathrm{U} / \mathrm{mL})$ and FCS $(10 \%)$ at $37^{\circ} \mathrm{C}$ in a $5 \%$ $\mathrm{CO}_{2}$ and $95 \%$ air atmosphere, for $24 \mathrm{~h}$. Next, VTs were cultured in DMEM/F12 medium supplemented with FCS (1\%) for $48 \mathrm{~h}$. VTs were exposed to FITC-dextran (Sigma) for $30 \mathrm{~min}, 1,2,3,4$ and $6 \mathrm{~h}$ at $37^{\circ} \mathrm{C}$. Next, the cells were fixed in paraformaldehyde $(4 \%)$ for $30 \mathrm{~min}$ at room temperature and washed with phosphate buffer saline for $45 \mathrm{~min}$ before counterstaining of the cell nuclei with $1 \mu \mathrm{g}$ / $\mathrm{mL}$ Hoechst 33258 Reagent (Sigma). The fluorescence was visualized using an inverted laser scanning confocal microscope (Leica white light laser TCS SP8-X, Leica Microsystem, Wetzlar, Germany). Five cell events per condition were randomly selected and the FITC-dextran intensity (in arbitrary units) was estimated using the postimaging procedure in ImageJ software. These experiments 
were designed to select the most efficient FITC-dextran exposure time for the VTs.

\section{Statistics}

Statistical analysis was performed on raw data from 5 to 10 separate experiments and compared with control values (i.e. in the absence of adiponectin) at D3, D8 and D15 in an ANOVA with Bonferroni $P$ value correction. A non-parametric, paired Wilcoxon test was used to assess (i) the effect of the adiponectin concentration $(25 \mathrm{ng} / \mathrm{mL}$ or $250 \mathrm{ng} / \mathrm{mL}$ ) with the control situation (the absence of adiponectin) for a given day of exposure.

\section{Results}

\section{Effect of adiponectin on glucose transporter and glucose uptake in human EnSCs}

We investigated the effect of adiponectin $(25 \mathrm{ng} / \mathrm{mL}$ or $250 \mathrm{ng} / \mathrm{mL}$ ) on mRNA expression levels of the glucose transporter isoforms 1 and 3 (GLUT1 and GLUT3) in EnSCs during decidualization. The GLUT1 mRNA expression level increased throughout the decidualization process (4.6-fold higher at D15 of cell culture relative to D3, $P<0.01$ ) (Fig. 1A). We found that adiponectin $(25 \mathrm{ng} / \mathrm{mL})$ accentuated the increase in GLUT1 mRNA expression (1.54-fold higher at D8 and 1.49-fold higher and D15, $P<0.05)$. Similarly, a significant increased GLUT1 mRNA expression was observed in presence of $250 \mathrm{ng} / \mathrm{mL}$ adiponectin (1.94-fold higher at D3, $P<0.05$; 2.70-fold higher and 2.29-fold higher at D3 and D15, respectively, $P<0.01)$. An opposite expression profile was observed for GLUT3 mRNA expression: in the absence of adiponectin, levels of GLUT3 mRNA expression fell during decidualization (3.1-fold lower at D15 of cell culture relative to D3, $P<0.05)$. Furthermore, neither of the two adiponectin concentrations affected the GLUT3 mRNA expression level at any time point (Fig. 1B). Western blot analysis showed that adiponectin $(250 \mathrm{ng} / \mathrm{mL})$ significantly increases GLUT1 expression at D15 of cell culture (3.2-fold higher relative to control) (Fig. 1C). In parallel, we measured the glucose levels in cell supernatants on D3, D8 and D15 of decidualization in the presence or absence of adiponectin $(25 \mathrm{ng} / \mathrm{mL}$ or $250 \mathrm{ng} / \mathrm{mL}$ ) (Fig. 1D). Our results showed that adiponectin $(25 \mathrm{ng} / \mathrm{mL})$ was associated with significantly lower glucose levels in supernatants $(81 \pm 7 \%, P<0.05)$ at D15 only. However, glucose levels were significantly lower at all time points in the presence of $250 \mathrm{ng} / \mathrm{mL}$ adiponectin $(91 \pm 4,83 \pm 3$, and $79 \pm 5 \%$, at respectively D3, D8 and D15, $P<0.05)$. Taken as a whole, these results suggest that adiponectin increases glucose uptake by EnSCs.

\section{Effect of adiponectin on glucose catabolism in human EnSCs}

In order to determine how decidualized EnSCs use the glucose in the presence of adiponectin, we quantified the cellular ATP levels and lactate release into the cell supernatant. Firstly, we compared cellular ATP levels in undifferentiated (D0) and differentiated (D15) EnSCs. In the absence of adiponectin, we did not observe any significant difference in ATP production between D0 and D15 $(67.4 \pm 2.8 \mu \mathrm{M}$ and $80.6 \pm 12.2 \mu \mathrm{M}$, respectively)
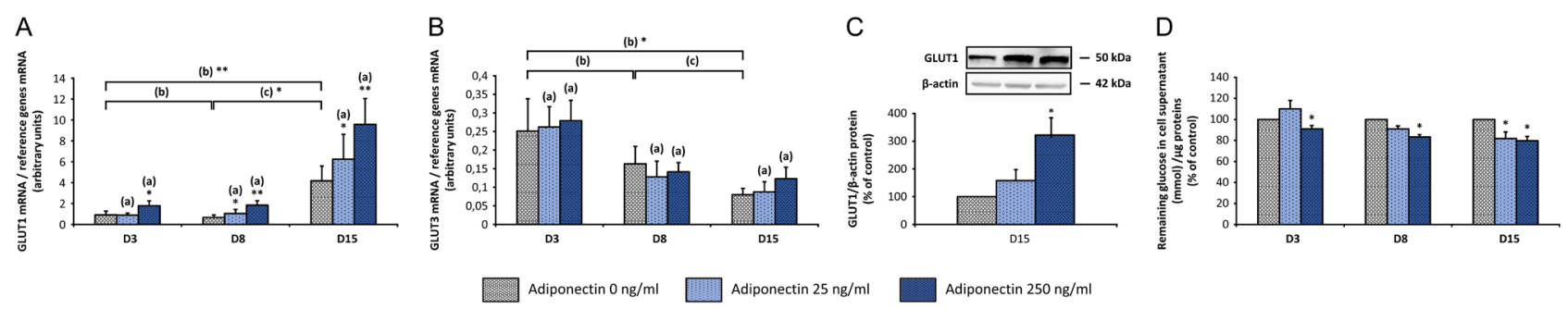

\section{Figure 1}

Adiponectin increases GLUT 1 expression and glucose uptake by EnSCs throughout decidualization. Human EnSCs were cultured in DMEM/F12 medium supplemented with E2 and P4 and exposed or not to adiponectin ( $25 \mathrm{ng} / \mathrm{mL}$ and $250 \mathrm{ng} / \mathrm{mL}$ ). (A and B) Total RNA was extracted after 3 (D3), 8 (D8) and 15 days (D15) of cell decidualization. GLUT1 and GLUT3 mRNA expression levels were quantified by RT-qPCR, as described in the 'Materials and methods' section. The data are quoted as the mean \pm s.E.M. of nine separate experiments. (A) GLUT1 mRNA expression. (B) GLUT3 mRNA expression. (C) Total protein were extracted at D15. GLUT1 Western blot and densitometric analysis were performed as described in 'Materials and methods' section. The data are quoted as the mean \pm S.E.M. of five separate experiments. The insert figure shows one representative of five separate experiments. (D) The glucose level in the supernatant was measured in supernatant after 3 (D3), 8 (D8) and 15 days (D15) of cell decidualization. The data are quoted as the mean \pm s.E.M. of six separate experiments. The control values were $14.31 \pm 1.63 \mathrm{mmol} / \mathrm{\mu g}$ protein at D3, $18.40 \pm 1.28 \mathrm{mmol} / \mu \mathrm{g}$ protein at D8, and $16.51 \pm 1.26 \mathrm{mmol} / \mathrm{\mu g}$ protein at D15. ${ }^{*} P<0.05 ; * * P<0.01$. (a) vs a control experiment in the absence of adiponectin. Wilcoxon test. (b) vs D3. ANOVA test. (c) vs D8. ANOVA test. A full colour version of this figure is available at https://doi.org/10.1530/JME-18-0013. 
(data not shown). However, incubation with adiponectin was associated with lower cellular ATP levels on D15 $(68.4 \pm 10.1 \%$ and $65.6 \pm 13.5 \%$ for $25 \mathrm{ng} / \mathrm{mL}$ and $250 \mathrm{ng} /$ $\mathrm{mL}$, respectively, $P<0.05$ ) (Fig. $2 \mathrm{~A}$ ). Secondly, we also observed that the presence of adiponectin was associated with significantly lower lactate production by EnSCs after 15 days of culture $(54 \pm 12 \%$ and $54.4 \pm 14.1 \%$ for $25 \mathrm{ng} /$ $\mathrm{mL}$ and $250 \mathrm{ng} / \mathrm{mL}$, respectively, $P<0.05$ ) (Fig. 2B).

\section{Effect of adiponectin on glycogen synthesis by human EnSCs}

As adiponectin did not seem to direct glucose toward anaerobic or aerobic glycolysis, we sought to determine its potential role in glycogen synthesis in human EnSCs. We therefore studied the expression of the main enzymes involved in glycogen hydrolysis (GP) and glycogen synthesis from glucose (GS). In the absence of adiponectin, the GS and GP mRNA expression levels did not change significantly during the EnSC decidualization. However, when EnSCs were treated with adiponectin for 15 days, we observed significantly higher levels of $G S$ mRNA expression (1.71-fold higher and 1.56-fold higher for $25 \mathrm{ng} / \mathrm{mL}$ and $250 \mathrm{ng} / \mathrm{mL}$, respectively, $P<0.05$ ) (Fig. 3A). In contrast, we did not observe any effect of adiponectin on GP mRNA expression at either concentration, whatever the time of exposure (Fig. 3B). In parallel, we measured glycogen accumulation in EnSCs on D15 of decidualization. We observed a positive effect of adiponectin on glycogen accumulation for high doses $(250,500$ and $1000 \mathrm{ng} / \mathrm{mL})$ (134 $\pm 10,184 \pm 30$ and $139 \pm 40 \%$, respectively, $P<0.05)$. However, in our experimental conditions, we did not observe any significant dose effect of adiponectin (Fig. 3C).

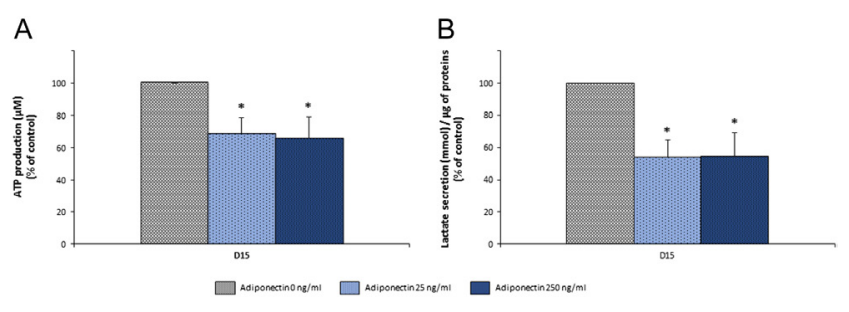

Figure 2

Adiponectin decreases glucose catabolism in EnSCs. Human EnSCs were cultured in DMEM/F12 medium supplemented with E2 and P4, and exposed or not to adiponectin $(25 \mathrm{ng} / \mathrm{mL}$ and $250 \mathrm{ng} / \mathrm{mL}$ ) for 15 days (D15) of cell decidualization. (A) Total ATP production was determined at D15. The data are quoted as the mean \pm s.E.M. of eight separate experiments. The control value was $80.59 \pm 12.17 \mu \mathrm{M}$ ATP. (B) Lactate production was measured at D15. The data are quoted as the mean \pm S.E.M. of six separate experiments. The control value was $2.08 \pm 0.66 \mathrm{mmol} / \mu \mathrm{g}$ protein. ${ }^{\star} P<0.05$ Wilcoxon test. A full colour version of this figure is available at https:// doi.org/10.1530/JME-18-0013.

\section{Effect of adiponectin on AMPK and PI3K activation in human EnSCs}

Our results suggested that adiponectin promotes glycogen synthesis and conversely blocks glucose catabolism in human EnSCs. Hence, we now sought to specify the signaling pathways involved in these adiponectin effects. Activation of AMPK and PI3K was evaluated by measuring the phosphorylation on the Thr-172 residue of AMPK $\alpha$ and on the Ser-9 residue of GSK3 $\beta$, respectively. As shown in Fig. 4A and B, we observed that adiponectin-treated EnSCs presented a lower phospho-AMPK $\alpha /$ total-AMPK $\alpha$ ratio at D15 $(81.6 \pm 4.7 \%$ and $74.9 \pm 5.5 \%$ for $25 \mathrm{ng} / \mathrm{mL}$ and $250 \mathrm{ng} / \mathrm{mL}$, respectively, $P<0.05)$ than non-treated EnSCs. In parallel, a higher phospho-GSK3 $\beta /$ total-GSK3 $\beta$ ratio was observed $(169 \pm 38 \%$ for $250 \mathrm{ng} / \mathrm{mL}$ adiponectin, $P<0.05$ ) (Fig. 4C and D).

\section{Signaling pathways involved in adiponectin regulation of glycogen accumulation in human EnsCs}

To precise the molecular mechanisms underlying adiponectin effects on glycogen accumulation in human EnSCs, we performed experiments with selective inhibitors and activators of AMPK and PI3K. Compound C $(1 \mu \mathrm{M})$ and LY294002 $(10 \mu \mathrm{M})$ were used as AMPK and PI3K inhibitors, respectively. Since AMPK and PI3K are key components of two major transduction pathways in glycogen metabolism, it is not surprising that both inhibitors exerted a significant effect on glycogen accumulation. A significant increase $(142 \pm 10 \%$ relative to the control, $P<0.05)$ and a significant reduction $(68.3 \pm 9.7 \%$ relative to the control, $P<0.05)$ in endometrial glycogen accumulation were effectively observed in the presence of Compound C and LY294002, respectively (Fig. 5). We confirmed the importance of PI3K pathway in EnSCs for glycogen accumulation. Indeed, we observed that the increased glycogen accumulation induced by adiponectin persisted in the presence of Compound C $(145.6 \pm 11.7 \%$ relative to the control, $P<0.05)$ but was abrogated by a treatment with LY294002 $(82 \pm 11 \%$ relative to control, $P<0.05)$.

\section{Effect of adiponectin on paracrine interaction between EnSCs and VTs}

We next sought to specify adiponectin effect on glycogen secretion by EnSCs. To this end, we quantified glycogen secretion into the cell supernatant in the presence or absence of adiponectin (Fig. 6A). Compared with 
A

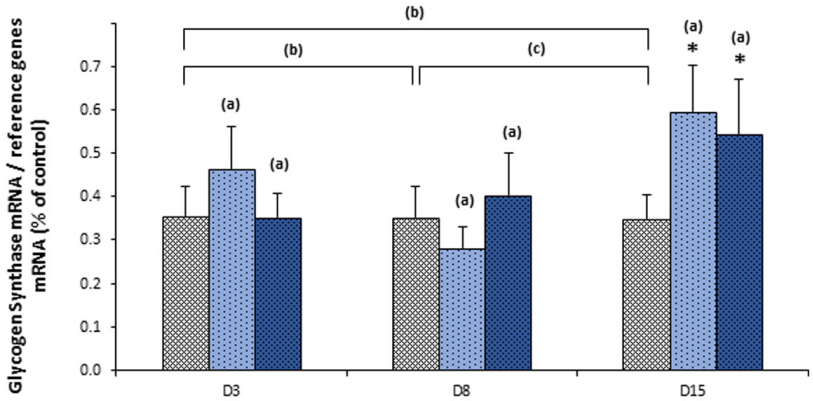

B
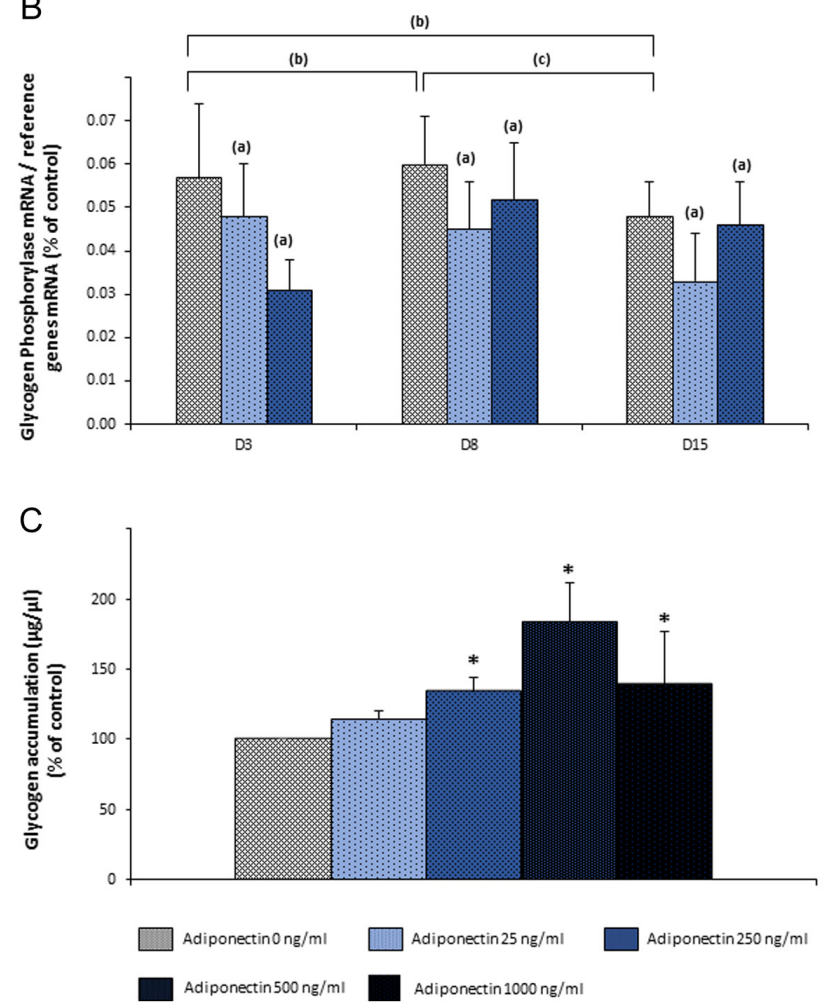

Figure 3

Adiponectin promotes glycogenesis in EnSCs. Human EnSCs were cultured in DMEM/F12 medium supplemented with E2 and P4 and exposed or not to adiponectin. ( $A$ and $B$ ) Human EnSCs were exposed or not to adiponectin ( $25 \mathrm{ng} / \mathrm{mL}$ and $250 \mathrm{ng} / \mathrm{mL}$ ). Total RNA was extracted after three (D3), eight (D8), and 15 days (D15) of cell decidualization. mRNA expression levels of GS and GP were quantified by RT-qPCR, as described in 'Materials and methods' section. The data are quoted as the mean \pm S.E.M. of nine separate experiments. (A) GS mRNA expression. (B) GP mRNA expression. (C) Human EnSCs were exposed or not to adiponectin $(25,250,500$ and $1000 \mathrm{ng} / \mathrm{mL})$ for 15 days (D15) of cell decidualization. Intracellular glycogen accumulation was determined at D15. The data are quoted as the mean \pm S.E.M. of eight separate experiments. The control value was $0.91 \pm 0.08 \mu \mathrm{g} / \mu \mathrm{L}$. ${ }^{*} P<0.05$. (a) vs a control experiment in the absence of adiponectin. Wilcoxon test. (b) vs D3. ANOVA test. (c) vs D8. ANOVA test. A full colour version of this figure is available at https://doi.org/10.1530/JME-18-0013.

the control situation, adiponectin increased glycogen secretion by EnSCs $(192 \pm 20 \%$ and $267 \pm 63 \%$ for $25 \mathrm{ng} / \mathrm{mL}$ and $250 \mathrm{ng} / \mathrm{mL}$, respectively, $P<0.05)$. We also observed
A
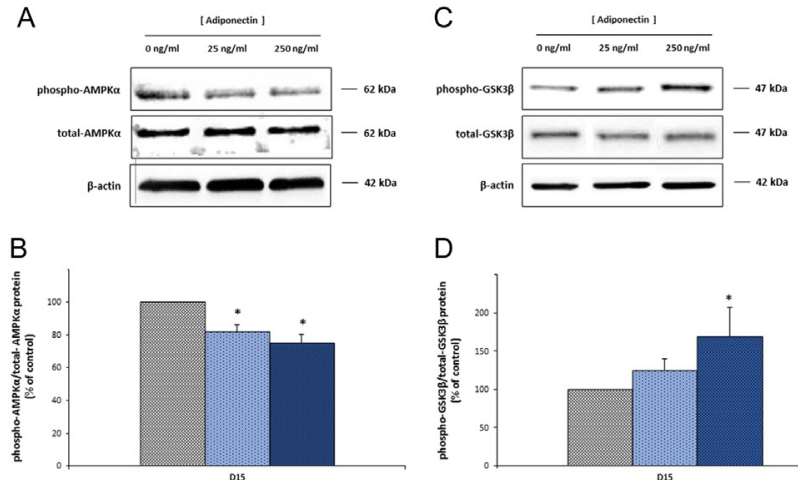

$\mathrm{D}$

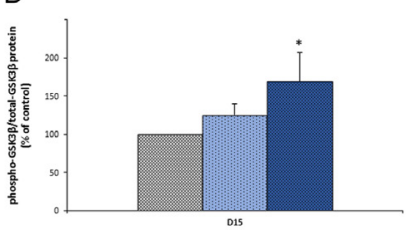

Figure 4

Adiponectin regulates glucose metabolism pathways in EnSCs. Human EnSCs were cultured in DMEM/F12 medium supplemented with E2 and P4 and exposed or not to adiponectin $(25 \mathrm{ng} / \mathrm{mL}$ and $250 \mathrm{ng} / \mathrm{mL}$ ) for 15 days (D15) of cell decidualization. Total protein were extracted at D15. (A) Phospho-AMPK $\alpha$ (Thr-172) and total-AMPK $\alpha$ Western blot analysis were realized. The figure represents one representative of five separate experiments. (B) Densitometric analysis of the active phospho-AMPK $\alpha$ (Thr-172)/total-AMPK $\alpha$ protein immunoblots was performed as described in the 'Materials and methods' section. (C) Phospho-GSK3 $\beta$ (Ser-9) and total-GSK3 $\beta$ Western blot analysis were realized. The figure represents one representative of five separate experiments. (D) Densitometric analysis of the active phospho-GSK3 $\beta$ (Ser-9)/total-GSK3 $\beta$ protein immunoblots was performed as described in the 'Materials and methods' section. The data are quoted as the mean \pm S.E.M. of five separate experiments. ${ }^{*} P<0.05$. Wilcoxon test. A full colour version of this figure is available at https://doi.org/10.1530/JME-18-0013.

that EnSCs not exposed to E2 and P4 treatment (i.e. nondecidualized EnSCs) secreted significantly lower amounts of glycogen $(39 \pm 14 \%$ relative to the control, $P<0.05)$.

In addition, in order to demonstrate whether the endometrial glycogen secreted by EnSCs was captured by placental cells, VT cultures were performed using CM from non-decidualized EnSCs (i.e. EnSCs cultured in the absence of E2 and P4) and from fully decidualized EnSCs treated or not with adiponectin for 15 days (Fig. 6B). First, we observed that VTs cultured with CM from fully decidualized EnSCs, accumulated higher glycogen quantities $(+48 \%)$ than those cultured with medium from non-decidualized EnSCs. Secondly, we demonstrated that medium enriched in glycogen (i.e. conditioned by adiponectin-treated EnSCs) increased glycogen accumulation in VTs $(116 \pm 12 \%$ and $112 \pm 8 \%$ for $25 \mathrm{ng} / \mathrm{mL}$ and $250 \mathrm{ng} / \mathrm{mL}$, relative to control, $P<0.05$ ).

\section{Effect of adiponectin on glycogen uptake by human VTs}

As illustrated in Fig. 7A and B, glycogen and dextran molecules are highly similar. Hence, we used FITC-dextran to study glycogen accumulation in VTs. In confocal 


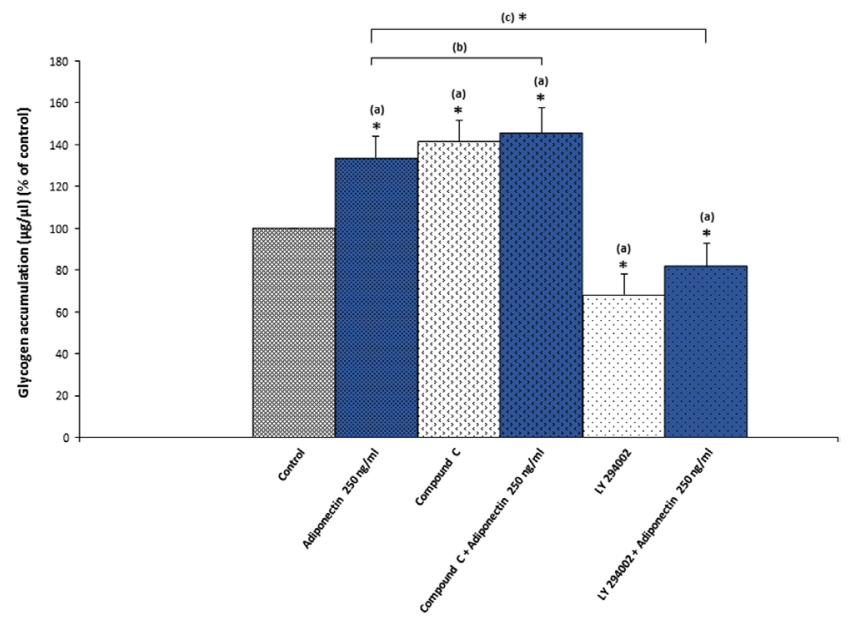

Figure 5

Adiponectin activates EnSC glycogen accumulation via PI3K pathway. Human EnSCs were cultured in DMEM/F12 medium supplemented with E2 and P4 and exposed or not to adiponectin $(250 \mathrm{ng} / \mathrm{mL})$ in presence or in absence of PI3K inhibitor (LY294002, 10-6 M) and AMPK inhibitor (Compound C, $10^{-6} \mathrm{M}$ ) for 15 days (D15) of cell decidualization. Intracellular glycogen accumulation was determined at D15. The data are quoted as the mean \pm S.E.M. of six separate experiments. The control value was $0.91 \pm 0.08 \mu \mathrm{g} / \mathrm{\mu L}$. ${ }^{*} P<0.05$. (a) vs control (without inhibitors nor adiponectin). (b) adiponectin + Compound $\mathrm{C}$ vs adiponectin alone. (c) adiponectin + LY294002 vs adiponectin alone. Wilcoxon test. A full colour version of this figure is available at https://doi.org/10.1530/JME-18-0013.

microscopy experiments, we confirmed that (i) VTs accumulated dextran at the concentrations described in the literature (i.e. $1 \mathrm{mg} / \mathrm{mL}$ ) and (ii) polysaccharide uptake by VTs appears to be optimal after $2 \mathrm{~h}$ of VT incubation with FITC-dextran (Fig. 7C). Next, VTs were cultured in the presence of adiponectin $(25 \mathrm{ng} / \mathrm{mL}$ or $250 \mathrm{ng} / \mathrm{mL})$ for $48 \mathrm{~h}$ and then exposed to FITC-dextran $(1 \mathrm{mg} / \mathrm{mL})$ for the last $2 \mathrm{~h}$. As shown in Fig. 7D, flow cytometry experiments showed that the mean FITC-dextran fluorescence intensity was significantly lower in VTs exposed to adiponectin $(82.4 \pm 4.2 \%$ and $82.3 \pm 8.1 \%$ for $25 \mathrm{ng} / \mathrm{mL}$ and $250 \mathrm{ng} / \mathrm{mL}$, respectively, relative to control, $P<0.05$ ).

\section{Discussion}

For many years, the endometrium (like the uterus in general) was considered to be an inert organ whose sole function was to support the developing fetus. However, a large body of data clearly now show that the endometrium has a critical role in the establishment of a successful pregnancy. More particularly, EnSCs accumulate and secrete large amounts of nutritive molecules (such as proteins, lipids and glycogen) and provide histiotrophic nutrition to the fetus via endocytosis by the ST (Burton et al. 2007). Endometrial glycogen seems to have a crucial role in the early stages of pregnancy. Indeed, it has been
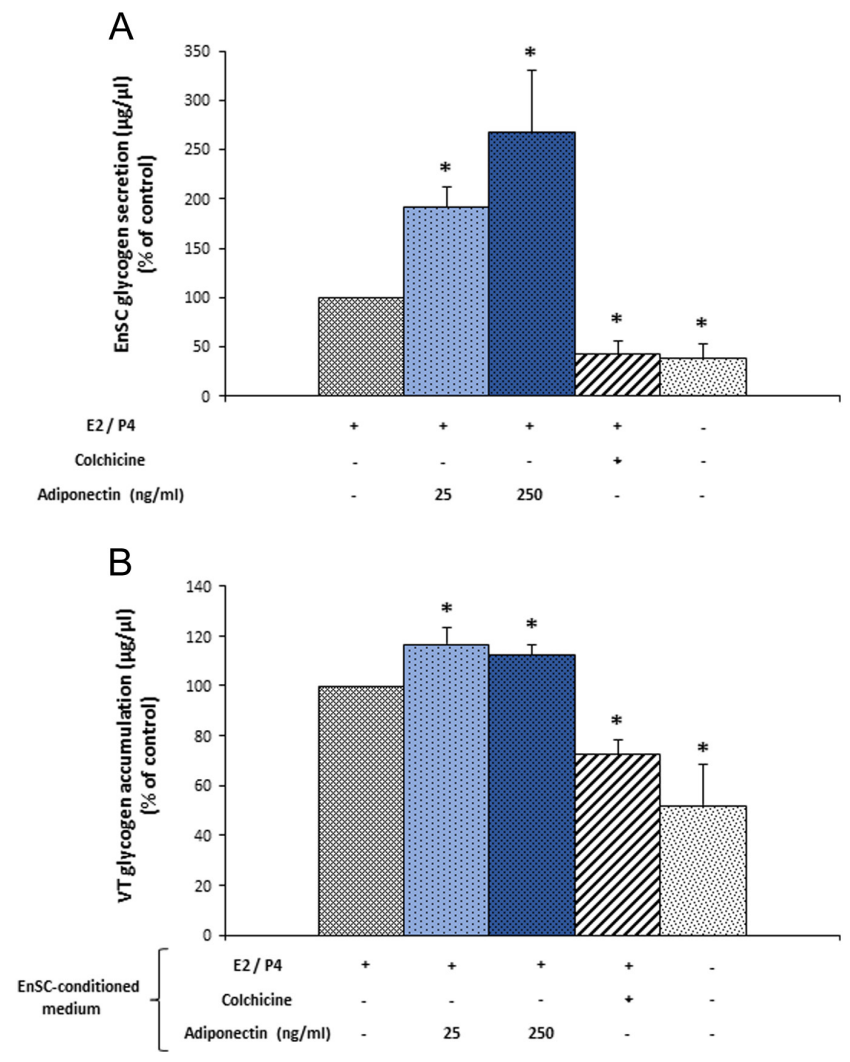

Figure 6

Adiponectin enhances EnSCs glycogen secretion and VT glycogen accumulation. (A) Human EnSCs were cultured in DMEM/F12 medium supplemented with E2 and P4 and exposed or not to adiponectin ( $25 \mathrm{ng} /$ $\mathrm{mL}$ and $250 \mathrm{ng} / \mathrm{mL}$ ) for 15 days (D15) of cell decidualization. Extracellular glycogen secretion was measured in cell supernatants at D15. The data are quoted as the mean \pm s.E.M. of eight separate experiments. The control value was $0.28 \pm 0.03 \mu \mathrm{g} / \mu \mathrm{L}$. (B) Human VTs were cultured in the presence of conditioned medium (CM) from fully decidualized EnSCs treated or not with adiponectin $(25 \mathrm{ng} / \mathrm{mL}$ or $250 \mathrm{ng} / \mathrm{mL}$ ) for 15 days (D15). As a negative control, VTs were cultured in the presence of CM from non-decidualized EnSCs (i.e. cultured without E2 and P4). After 48 h, intracellular glycogen accumulation in VTs was measured. The data are quoted as the mean \pm s.E.M. of ten separate experiments. The control value was $0.77 \pm 0.13 \mu \mathrm{g} / \mu \mathrm{L}$. ${ }^{*} P<0.05$. Wilcoxon test. A full colour version of this figure is available at https://doi.org/10.1530/JME-18-0013.

reported that endometrial glycogen levels are lower in infertile women than in fertile women (Maeyama et al. 1977). In order to better understand glycogen metabolism at the fetal-maternal interface, we studied the effects of adiponectin (a key actor of paracrine dialog at the interface) on (i) glucose catabolism and (ii) glycogen accumulation and secretion in human endometrial cells. We also assessed adiponectin effects on glycogen uptake by human trophoblastic cells. In the present study, human recombinant adiponectin had effects at concentrations of $25 \mathrm{ng} / \mathrm{mL}$ and $250 \mathrm{ng} / \mathrm{mL}$, which are much lower than those normally found in the main circulation or in cord blood during pregnancy (Kajantie et al. 2004, 
A

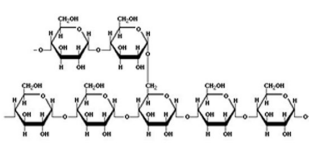

Glycogen structure

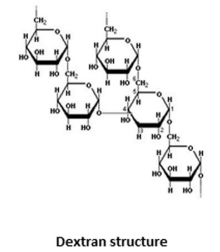

C
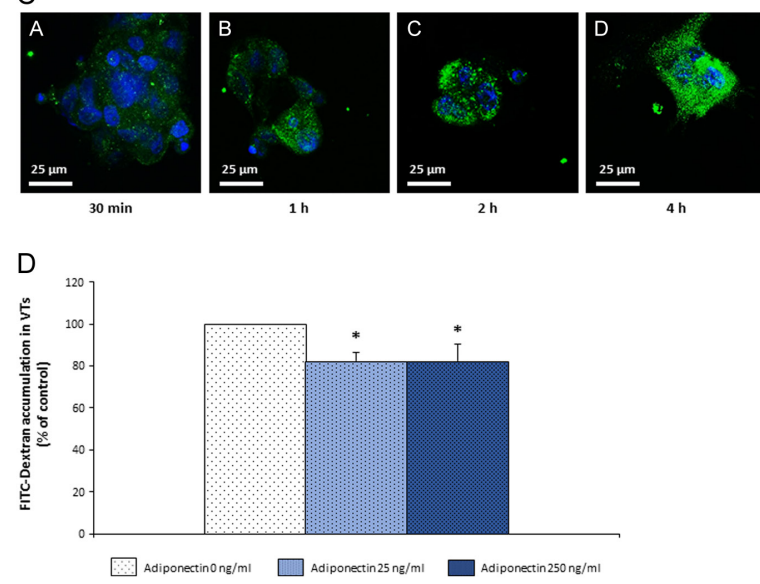

\section{Figure 7}

Adiponectin decreases FITC-dextran uptake by VTs. (A) The structure of glycogen. (B) The structure of dextran. (C) VTs were incubated with FITC-dextran as described in the 'Materials and methods' section. FITC-dextran absorption was analyzed by confocal microscopy. Magnification $\times 40$. The figure represents one representative of three separate experiments. (a) 30-min incubation. (b) 1-h incubation. (c) 2-h incubation. (d) 4-h incubation. (D) VTs cultured for 3 days and incubated for the two last hours with FITCdextran. Quantification of FITC-dextran absorption by VTs with or without adiponectin ( $25 \mathrm{ng} / \mathrm{mL}$ and $250 \mathrm{ng} / \mathrm{mL}$ ) was performed as described in the 'Materials and methods' section. The data are quoted as the mean \pm S.E.M. of ten separate experiments. ${ }^{*} P<0.05$. Wilcoxon test. A full colour version of this figure is available at https://doi.org/10.1530/JME-18-0013.
Corbetta et al. 2005). However, the human recombinant adiponectin used in the present study corresponds mainly to the oligomeric form (Bub et al. 2006), which is known to be an active form of adiponectin (Kobayashi et al. 2004). Moreover, adiponectin is commonly used in in vitro experiments with endometrial, placental and other cell types at these sub-physiological concentrations (Brakenhielm et al. 2004, Benaitreau et al. 2009, 2010a,b, Bohlouli et al. 2013, Duval et al. 2016, 2017). We also studied physiological doses of adiponectin $(500 \mathrm{ng} / \mathrm{mL}$ and $1000 \mathrm{ng} / \mathrm{mL}$ ) on glycogen accumulation. However, we did not observe any significant dose-dependent effect of adiponectin. This result is in accordance with previous data described in human placenta and endometrium (Benaitreau et al. 2010a,b, Bohlouli et al. 2013, Duval et al. 2016, 2017). In a first set of experiments, we studied glucose catabolism in human EnSCs. In the absence of adiponectin, we observed a major increase over time in mRNA expression of glucose transporter GLUT1 during cell differentiation. Surprisingly, mRNA expression levels of GLUT3 (another glucose transporter isoform expressed in human endometrium) decreased slightly during EnSC differentiation. These results suggest that GLUT1 becomes the major isoform in fully differentiated EnSCs, as previously described in human endometrial and decidual tissues during the menstrual cycle (Strowitzki et al. 2001, Krzeslak et al. 2012).

In parallel, we studied adiponectin effects on GLUT1 and GLUT3 expressions by EnSCs. Our results clearly demonstrated that adiponectin increases GLUT1 expression (at mRNA and protein levels) without affecting GLUT3 mRNA expression. These results suggested that adiponectin could promote glucose uptake by increasing specifically GLUT1 expression in EnSCs. Moreover, we showed that exposure to adiponectin was associated with a significant decrease in the catabolic glucose pathways (anaerobic and aerobic glycolysis) and conversely, a relative increase in glucose anabolism (by directly inducing GS mRNA expression, the rate limiting enzyme in glycogen synthesis). These results suggest that adiponectin has a broader range of effects on glucose metabolism in EnSCs than in hepatocytes, a well-characterized cell target in which adiponectin specifically controls glycogenolysis and gluconeogenesis (Combs \& Marliss 2014).

Our results also demonstrated that adiponectin favors the accumulation of glycogen in EnSCs. It is well known that the AMPK and PI3K signal transduction pathways are both involved in glycogen metabolism in skeletal muscle and in the liver (Bultot et al. 2012, Khorami et al. 2015). To gain insight into the molecular mechanisms involved in glycogen accumulation in response to adiponectin, we investigated the two main adiponectin pathways. First, our results revealed that adiponectin is able to stimulate PI3K and inversely to inhibit AMPK, suggesting that both ADIPOR1 and ADIPOR2 are functional in EnSCs. Secondly, the results of experiments with specific inhibitors demonstrated that adiponectin promotes glycogen storage specifically via the PI3K transduction pathway. Hence, we can hypothesize that AMPK signaling is involved in other physiological effects of adiponectin such as endometrial glucose catabolism. Further experiments are underway in our laboratory.

It is well established that glycogen secretion by endometrial cells is an apocrine secretory mechanism (Bergeron 2000, Demir et al. 2002). More precisely, intracellular glycogen-enriched vacuoles appear in endometrial cell cytoplasm, under the influence of progesterone. These vacuoles induce the detachment 
of the apical region of endometrial cells resulting in the glycogen discharge from the endometrial cell. In this context, we have studied the direct effects of adiponectin on glycogen secretion by EnSCs during in vitro decidualization. We found that glycogen secretion appears to depend on the EnSC decidualization status since EnSCs cultured in the absence of E2, and P4 secreted less glycogen than fully decidualized EnSCs. These data confirm and complete several previous studies performed with endometrial glands demonstrating that glycogen content is associated with decidualization status (Salameh et al. 2006, Rose et al. 2011, Dean et al. 2014, Filant \& Spencer 2014). Moreover, we showed that EnSCs treated with adiponectin secreted significantly higher amounts of glycogen than non-treated cells. Taken as a whole, our results clearly demonstrated that adiponectin improves endometrial glycogen secretion by stimulating the endometrial glycogen accumulation.

We next sought to establish whether placental cells are able to take up endometrial glycogen. To this end, VTs were plated in the presence of CM from EnSCs cultured in the presence or in the absence of adiponectin. We clearly demonstrated that VTs treated with glycogenenriched medium (i.e. CM from adiponectin-treated EnSCs) accumulate greater amounts of glycogen in their cytoplasm than VTs treated with low-glycogen medium (i.e. CM from EnSCs not treated with adiponectin or EnSCs not treated with E2 and P4). These results suggest that VT glycogen uptake (i) depends on the amount of glycogen in the extracellular medium and (ii) seems to be controlled by adiponectin. In fact, our experiments performed with FITC-dextran revealed that adiponectin directly controls trophoblast glycogen uptake. Adiponectin can also indirectly control this process by stimulating the secretion of endometrial factors. Epidermal growth factor seems to be a good candidate since it is secreted by EnSCs and is known to increase glycogen uptake by hepatocytes (Freemark 1986, Burton et al. 2007).

Lastly, we found that internalized glycogen co-localized first with endosomes (Supplementary Fig. 1, see section on supplementary data given at the end of this article) and then with lysosomes (Supplementary Fig. 2). The latter results are in line with the literature data on the trafficking of macromolecules (including glycogen) between decidual glands and trophoblasts (Jones et al. 2015). Hence, we can hypothesize that after placental endocytosis, endometrial glycogen is degraded (like proteins) in lysosomes (Supplementary Figs 1, 2 and 3). The newly formed glucose molecules are probably used by VTs for their own metabolic needs or transmitted to the fetus via the histiotrophic nutrition pathway. Further experiments will be needed to confirm this hypothesis and to specify adiponectin roles in placental glycophagy.

In conclusion, our present results show that adiponectin promotes glycogen synthesis, accumulation and secretion by human EnSCs. However, adiponectin also slows down glycogen entry into human VTs, suggesting that adiponectin downregulates the placenta uptake of

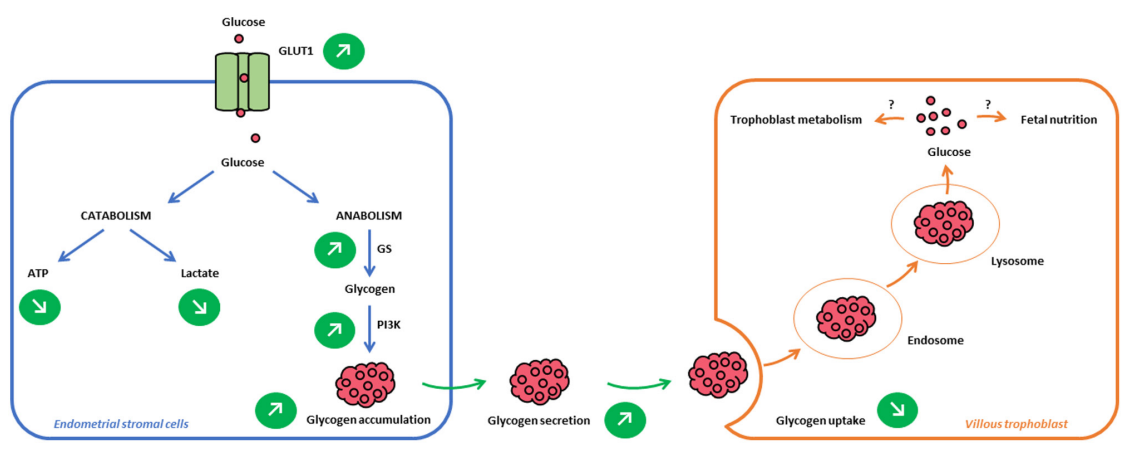

http://jme.endocrinology-journals.org https://doi.org/10.1530/JME-18-0013 (c) 2018 Society for Endocrinology Published by Bioscientifica Ltd. Printed in Great Britain
Figure 8

Proposed mechanism by which adiponectin controls glycogen metabolism and trafficking at the fetal-maternal interface. In human EnSCs, adiponectin stimulates glucose uptake by upregulating GLUT1 mRNA expression. Then, adiponectin significantly reduces the catabolic glucose pathways (anaerobic and aerobic glycolysis) and conversely increases both glycogen synthesis (by directly inducing GS mRNA expression) and glycogen accumulation. This last effect is, in part, mediated by PI3K transduction signaling. Glycogen secretion being an apocrine mechanism, adiponectin also improves glycogen secretion. At the feto-maternal interface, adiponectin limits glycogen uptake by VTs. Once endocytosis, glycogen is directed toward lysosomes in order to be degraded into glucose. Glucose could then be used by placental cells for its own metabolic needs, or transmitted to the fetus in order to insure fetal nutrition. GS, glycogen synthase; $\nearrow$, increase; \, inhibition. A full colour version of this figure is available at https://doi.org/10.1530/JME-18-0013 
nutrients through the histiotrophic nutrition pathway. Indeed, we and others have reported that adiponectin inhibits nutrient transporters expression in the firsttrimester and third-trimester human placenta as well as in the murine placenta (Caminos et al. 2005, Jones et al. 2010, Aye et al. 2014, Duval et al. 2016). Interestingly, opposite effects of adiponectin in the endometrium and the placenta have been already described. Indeed, we found that adiponectin induces pro-invasive effects in human VTs (Benaitreau et al. 2010b) but anti-invasive effects in human EnSCs (Duval et al. 2017). Furthermore, we demonstrated that adiponectin promotes aerobic glycolysis and ATP synthesis in human placental cells (Duval et al. 2016). In the present study, we found that adiponectin had the opposite effect in human EnSCs. Moreover, adiponectin has proinflammatory effects in the endometrium and anti-inflammatory effects in the placenta (Lappas et al. 2005, Takemura et al. 2006).

Studies performed in our laboratory revealed that adiponectin exerts pro-differentiative, pro-invasive and pro-apoptotic effects in human placental cells and conversely, anti-differentiative and anti-invasive effects in human EnSCs. Our work highlighted a novel effect of adiponectin in both cell types. Taken as a whole, our present data suggest that this adipokine is a major actor at the fetal-maternal interface. Thus, dysfunctional adiponectin signaling (due to a low endometrial ADIPOR expression, for example) might jeopardize a successful pregnancy - as we have shown previously in our study of endometrial tissue from women with unexplained recurrent implantation failure (Santos et al. 2012). The role of adiponectin in glycogen metabolism and trafficking at the fetal-maternal interface during the first trimester of pregnancy is summarized in Fig. 8.

Supplementary data

This is linked to the online version of the paper at https://doi.org/10.1530/ JME-18-0013.

\section{Declaration of interest}

The authors declare that there is no conflict of interest that could be perceived as prejudicing the impartiality of the research reported.

\section{Funding}

This work was funded by the Institut de Recherche en Santé de la Femme, based at the UFR des Sciences de la Santé, University of Versailles-SaintQuentin-en-Yvelines and the Maternité et Médecine de la Reproduction Association, based at the $\mathrm{CHI}$ de Poissy-Saint-Germain-en-Laye.
Author contributions statement

F D and M-N D designed the experiments. F D performed the experiments. F D and M-N D analyzed the data. F D, M-N D and E D S wrote the manuscript. K F provided human endometrial biopsies and placenta tissues for experiments. V S performed automated assays. B M contributed to analyze the confocal data. $\mathrm{F} V$ obtained research funding and critically revised the manuscript.

\section{Acknowledgements}

The authors gratefully acknowledge the staff at the Department of Gynecology and Obstetrics at $\mathrm{CHI}$ de Poissy-Saint-Germain-enLaye for kindly providing human endometrial and placental tissues. Immunofluorescence image acquisition and analysis were performed at the CYMAGES facility, supported by the Saint-Quentin-en-Yvelines Urban Community and the University of Versailles-Saint-Quentin-en-Yvelines. The authors thank Julien Tardieu for technical support.

\section{References}

Aye ILMH, Gao X, Weintraub ST, Jansson T \& Powell TL 2014 Adiponectin inhibits insulin function in primary trophoblasts by PPAR $\alpha$-mediated ceramide synthesis. Molecular Endocrinology 28 512-524. (https://doi.org/10.1210/me.2013-1401)

Benaitreau D, Dieudonné M-N, Dos Santos E, Leneveu M-C, de Mazancourt P \& Pecquery R 2009 Antiproliferative effects of adiponectin on human trophoblastic cell lines JEG-3 and BeWo. Biology of Reproduction 80 1107-1114. (https://doi.org/10.1095/ biolreprod.108.070573)

Benaitreau D, Dos Santos E, Leneveu M-C, Alfaidy N, Feige J-J, de Mazancourt P, Pecquery R \& Dieudonné M-N 2010 $a$ Effects of adiponectin on human trophoblast invasion. Journal of Endocrinology 207 45-53. (https://doi.org/10.1677/JOE-10-0170)

Benaitreau D, Dos Santos E, Leneveu M-C, De Mazancourt P, Pecquery R \& Dieudonné M-N 2010b Adiponectin promotes syncytialisation of BeWo cell line and primary trophoblast cells. Reproductive Biology and Endocrinology 8 128. (https://doi.org/10.1186/1477-7827-8-128)

Bergeron C 2000 Morphological changes and protein secretion induced by progesterone in the endometrium during the luteal phase in preparation for nidation. Human Reproduction 15 119-128. (https:// doi.org/10.1093/humrep/15.suppl_1.119)

Bohlouli S, Khazaei M, Teshfam M \& Hassanpour H 2013 Adiponectin effect on the viability of human endometrial stromal cells and mRNA expression of adiponectin receptors. International Journal of Fertility and Sterility 7 43-48.

Brakenhielm E, Veitonmaki N, Cao R, Kihara S, Matsuzawa Y, Zhivotovsky B, Funahashi T \& Cao Y 2004 Adiponectin-induced antiangiogenesis and antitumor activity involve caspase-mediated endothelial cell apoptosis. PNAS 101 2476-2481. (https://doi. org/10.1073/pnas.0308671100)

Bub JD, Miyazaki T \& Iwamoto Y 2006 Adiponectin as a growth inhibitor in prostate cancer cells. Biochemical and Biophysical Research Communications 340 1158-1166. (https://doi.org/10.1016/j. bbrc.2005.12.103)

Bultot L, Guigas B, Von Wilamowitz-Moellendorff A, Maisin L, Vertommen D, Hussain N, Beullens M, Guinovart JJJ, Foretz M, Viollet B, et al. 2012 AMP-activated protein kinase phosphorylates and inactivates liver glycogen synthase. Biochemical Journal $\mathbf{4 4 3}$ 193-203. (https://doi.org/10.1042/BJ20112026)

Burton GJ, Watson AL, Hempstock J, Skepper JN \& Jauniaux E 2002 Uterine glands provide histiotrophic nutrition for the human fetus during the first trimester of pregnancy. Journal of Clinical http://jme.endocrinology-journals.org https://doi.org/10.1530/JME-18-0013
(C) 2018 Society for Endocrinology Published by Bioscientifica Ltd. Printed in Great Britain 
Endocrinology and Metabolism 87 2954-2959. (https://doi. org/10.1210/jcem.87.6.8563)

Burton GJ, Jauniaux E \& Charnock-Jones DS 2007 Human early placental development: potential roles of the endometrial glands. Placenta 28 S64-S69. (https://doi.org/10.1016/j.placenta.2007.01.007)

Burton GJ, Scioscia M \& Rademacher TW 2011 Endometrial secretions: creating a stimulatory microenvironment within the human early placenta and implications for the aetiopathogenesis of preeclampsia. Journal of Reproductive Immunology 89 118-125. (https://doi. org/10.1016/j.jri.2011.02.005)

Caminos JE, Nogueiras R, Gallego R, Bravo S, Tovar S, GarcíaCaballero T, Casanueva FF \& Diéguez C 2005 Expression and regulation of adiponectin and receptor in human and rat placenta. Journal of Clinical Endocrinology and Metabolism 90 4276-4286. (https://doi.org/10.1210/jc.2004-0930)

Ceddia RB, Somwar R, Maida A, Fang X, Bikopoulos G \& Sweeney G 2005 Globular adiponectin increases GLUT4 translocation and glucose uptake but reduces glycogen synthesis in rat skeletal muscle cells. Diabetologia 48 132-139. (https://doi.org/10.1007/s00125-0041609-y)

Combs TP \& Marliss EB 2014 Adiponectin signaling in the liver. Reviews in Endocrine and Metabolic Disorders 15 137-147. (https://doi. org/10.1007/s11154-013-9280-6)

Corbetta S, Bulfamante G, Cortelazzi D, Barresi V, Cetin I, Mantovani G, Bondioni S, Beck-Peccoz P \& Spada A 2005 Adiponectin expression in human fetal tissues during mid- and late gestation. Journal of Clinical Endocrinology and Metabolism 90 2397-2402. (https://doi org/10.1210/jc.2004-1553)

Dean M, Hunt J, McDougall L \& Rose J 2014 Uterine glycogen metabolism in mink during estrus, embryonic diapause and pregnancy. Journal of Reproduction and Development 60 438-446. (https://doi.org/10.1262/jrd.2014-013)

Demir R, Kayisli UA, Celik-Ozenci C, Korgun ET, Demir-Weusten AY \& Arici A 2002 Structural differentiation of human uterine luminal and glandular epithelium during early pregnancy: an ultrastructural and immunohistochemical study. Placenta 23 672-684. (https://doi. org/10.1053/plac.2002.0841)

Dieudonne M-N, Bussiere M, Dos Santos E, Leneveu M-C, Giudicelli Y \& Pecquery R 2006 Adiponectin mediates antiproliferative and apoptotic responses in human MCF7 breast cancer cells. Biochemical and Biophysical Research Communications 345 271-279. (https://doi. org/10.1016/j.bbrc.2006.04.076)

Duval F, Dos Santos E, Poidatz D, Sérazin V, Gronier H, Vialard F \& Dieudonné M-N 2016 Adiponectin inhibits nutrient transporters and promotes apoptosis in human villous cytotrophoblasts: involvement in the control of fetal growth. Biology of Reproduction 94 1-12.

Duval F, Dos Santos E, Moindjie H, Serazin V, Swierkowski-Blanchard N, Vialard F \& Dieudonné M-N 2017 Adiponectin limits differentiation and trophoblast invasion in human endometrial cells. Journal of Molecular Endocrinology 59 285-297. (https://doi.org/10.1530/JME-170046)

Filant J \& Spencer TE 2014 Uterine glands: biological roles in conceptus implantation, uterine receptivity and decidualization. International Journal of Developmental Biology 58 107-116. (https://doi. org/10.1387/ijdb.130344ts)

Freemark M 1986 Epidermal growth factor stimulates glycogen synthesis in fetal rat hepatocytes: comparison with the glycogenic effects of insulin-like growth factor I and insulin. Endocrinology 119 522-526. (https://doi.org/10.1210/endo-119-2-522)

Hempstock J, Cindrova-Davies T, Jauniaux E \& Burton GJ 2004 Endometrial glands as a source of nutrients, growth factors and cytokines during the first trimester of human pregnancy: a morphological and immunohistochemical study. Reproductive Biology and Endocrinology 2 58-72. (https://doi.org/10.1186/1477-7827-2-58)

Irwin JC, Kirk D, King RJ, Quigley MM \& Gwatkin RB 1989 Hormonal regulation of human endometrial stromal cells in culture: an in vitro model for decidualization. Fertility and Sterility 52 761-768. (https:// doi.org/10.1016/S0015-0282(16)61028-2)

Jones HN, Jansson T \& Powell TL 2010 Full-length adiponectin attenuates insulin signaling and inhibits insulin-stimulated amino acid transport in human primary trophoblast cells. Diabetes $\mathbf{5 9}$ 1161-1170. (https://doi.org/10.2337/db09-0824)

Jones CJPJP, Choudhury RHH \& Aplin JDD 2015 Tracking nutrient transfer at the human maternofetal interface from 4 weeks to term. Placenta 36 372-380. (https://doi.org/10.1016/j. placenta.2015.01.002)

Kajantie E, Hytinantti T, Hovi P \& Andersson S 2004 Cord plasma adiponectin: a 20 -fold rise between 24 weeks gestation and term. Journal of Clinical Endocrinology and Metabolism 89 4031-4036. (https://doi.org/10.1210/jc.2004-0018)

Kaur J \& Debnath J 2015 Autophagy at the crossroads of catabolism and anabolism. Nature Reviews Molecular Cell Biology 16 461-472. (https:// doi.org/10.1038/nrm4024)

Khorami SAH, Movahedi A, Huzwah K \& Sokhini MMA 2015 PI3K/AKT pathway in modulating glucose homeostasis and its alteration in Diabetes. Annals of Biomedical Engineering 1 46-55.

Kobayashi H, Ouchi N, Kihara S, Walsh K, Kumada M, Abe Y, Funahashi T \& Matsuzawa Y 2004 Selective suppression of endothelial cell apoptosis by the high molecular weight form of adiponectin. Circulation Research 94 e27-e31. (https://doi. org/10.1161/01.RES.0000119921.86460.37)

Krzeslak A, Wojcik-Krowiranda K, Forma E, Jozwiak P, Romanowicz H, Bienkiewicz A \& Brys M 2012 Expression of GLUT1 and GLUT3 glucose transporters in endometrial and breast cancers. Pathology and Oncology Research 18 721-728. (https://doi.org/10.1007/s12253-0129500-5)

Lappas M, Permezel M \& Rice GE 2005 Leptin and adiponectin stimulate the release of proinflammatory cytokines and prostaglandins from human placenta and maternal adipose tissue via nuclear factor-kB, peroxisomal proliferator-activated receptor- $\gamma$ and extracellularly regulated kinase 1/2. Endocrinology 146 3334-3342. (https://doi.org/10.1210/en.2005-0406)

Lunghi L, Ferretti ME, Medici S, Biondi C \& Vesce F 2007 Control of human trophoblast function. Reproductive Biology and Endocrinology 5 6-20. (https://doi.org/10.1186/1477-7827-5-6)

Machinal-Quélin F, Dieudonné MN, Leneveu MC, Pecquery R \& Giudicelli Y 2002 Proadipogenic effect of leptin on rat preadipocytes in vitro: activation of MAPK and STAT3 signaling pathways. American Journal of Physiology: Cell Physiology 282 C853-C863.

Maeyama M, Sudo I, Saito K, Matsuo I \& Nakahara K 1977 Glycogen estimation by a rapid enzymic method in very small samples of human endometrium: glycogen content in the endometrium of infertile patients during the menstrual cycle. Fertility and Sterility $\mathbf{2 8}$ 159-162. (https://doi.org/10.1016/S0015-0282(16)42375-7)

Mimori H, Fukuma K, Matsuo I, Nakahara K \& Maeyama M 1981 Effect of progestogen on glycogen metabolism in the endometrium of infertile patients during the menstrual cycle. Fertility and Sterility $\mathbf{3 5}$ 289-295. (https://doi.org/10.1016/S0015-0282(16)45373-2)

Ouchi N, Kihara S, Arita Y, Okamoto Y, Maeda K, Kuriyama H, Hotta K, Nishida M, Takahashi M, Muraguchi M, et al. 2000 Adiponectin, an adipocyte-derived plasma protein, inhibits endothelial NF-kappaB signaling through a cAMP-dependent pathway. Circulation 102 1296-1301. (https://doi.org/10.1161/01.CIR.102.11.1296)

Poidatz D, Dos Santos E, Gronier H, Vialard F, Maury B, De Mazancourt P \& Dieudonne M-N 2015 Trophoblast syncytialisation necessitates mitochondrial function through estrogen-related receptor-activation. Molecular Human Reproduction 21 206-216. (https://doi.org/10.1093/molehr/gau102)

Poidatz DE, Dos Santos E, Lose Gronier H, Vialard F, Maury B, De Mazancourt P \& Dieudonné M-N 2014 Trophoblast syncytialisation necessitates mitochondrial function through estrogen-related receptor-g activation. Molecular Human Reproduction 2 206-216. 
Qiao L, Kinney B, Yoo HS, Lee B, Schaack J \& Shao J 2012 Adiponectin increases skeletal muscle mitochondrial biogenesis by suppressing mitogen-activated protein kinase phosphatase-1. Diabetes 61 1463-1470. (https://doi.org/10.2337/db11-1475)

Rosario FJ, Schumacher MA, Jiang J, Kanai Y, Powell TL \& Jansson T 2012 Chronic maternal infusion of full-length adiponectin in pregnant mice down-regulates placental amino acid transporter activity and expression and decreases fetal growth. Journal of Physiology 590 1495-1509. (https://doi.org/10.1113/ jphysiol.2011.226399)

Rose J, Hunt J, Shelton J, Wyler S \& Mecham D 2011 The effects of estradiol and catecholestrogens on uterine glycogen metabolism in mink (Neovison vison). Theriogenology 75 857-866. (https://doi. org/10.1016/j.theriogenology.2010.10.028)

Salameh W, Helliwell JP, Han G, Mcphaul L \& Khorram O 2006 Expression of endometrial glycogen synthase kinase-3b protein throughout the menstrual cycle and its regulation by progesterone. Molecular Human Reproduction 12 543-549. (https://doi.org/10.1093/ molehr/gal065)

Salker MS, Singh Y, Zeng N, Chen H, Zhang S, Umbach AT, Fakhri H, Kohlhofer U, Quintanilla-Martinez L, Durairaj RRP, et al. 2017 Loss of endometrial sodium glucose cotransporter SGLT1 is detrimental to embryo survival and fetal growth in pregnancy. Scientific Reports 7 12612-12622. (https://doi.org/10.1038/s41598-017-11674-3)

Santos E Dos, Serazin V, Morvan C, Torre A, Wainer R, De Mazancourt P \& Dieudonné MN 2012 Adiponectin and leptin systems in human endometrium during window of implantation. Fertility and Sterility 97 771-778. (https://doi.org/10.1016/j.fertnstert.2011.12.042)

Simionescu N, Simionescu M \& Palade GE 1972 Permeability of intestinal capillaries. Pathway followed by dextrans and glycogens. Journal of Cell Biology 53 365-392. (https://doi.org/10.1083/ jcb.53.2.365)

Strowitzki T, Capp E, von Wolff M \& Müller-Höcker J 2001 Expression of glucose transporter 1 in human endometrial and decidual tissue.
Gynecological Endocrinology 15 219-224. (https://doi.org/10.1080/ gye.15.3.219.224)

Takemura Y, Osuga Y, Yamauchi T, Kobayashi M, Harada M, Hirata T, Morimoto C, Hirota Y, Yoshino O, Koga K, et al. 2006 Expression of adiponectin receptors and its possible implication in the human endometrium. Endocrinology 147 3203-3210. (https://doi. org/10.1210/en.2005-1510)

Takikita S, Myerowitz R, Schreiner C, Baum R, Raben N \& Plotz PH 2009 The values and limits of an in vitro model of Pompe disease. Autophagy. 5 729-731. (https://doi.org/10.4161/auto.5.5.8525)

Tarrade A, Lai Kuen R, Malassiné A, Tricottet V, Blain P, Vidaud M \& Evain-Brion D 2001 Characterization of human villous and extravillous trophoblasts isolated from first trimester placenta. Laboratory Investigation 81 1199-1211. (https://doi.org/10.1038/ labinvest.3780334)

Yamauchi T, Kamon J, Waki H, Terauchi Y, Kubota N, Hara K, Mori Y, Ide T, Murakami K, Tsuboyama-Kasaoka N, et al. 2001 The fatderived hormone adiponectin reverses insulin resistance associated with both lipoatrophy and obesity. Nature Medicine 7 941-946. (https://doi.org/10.1038/90984)

Yamauchi T, Kamon J, Minokoshi Y, Ito Y, Waki H, Uchida S, Yamashita S, Noda M, Kita S, Ueki K, et al. 2002 Adiponectin stimulates glucose utilization and fatty-acid oxidation by activating AMP-activated protein kinase. Nature Medicine 8 1288-1295. (https:// doi.org/10.1038/nm788)

Yamauchi T, Hara K, Kubota N, Terauchi Y, Tobe K, Froguel P, Nagai R \& Kadowaki T 2003a Dual roles of adiponectin/Acrp30 in vivo as an anti-diabetic and anti-atherogenic adipokine. Current Drug Targets: Immune Endocrine and Metabolic Disorders 3 243-254. (https://doi. org/10.2174/1568008033340090)

Yamauchi T, Kamon J, Ito Y, Tsuchida A, Yokomizo T, Kita S, Sugiyama T, Miyagishi M, Hara K, Tsunoda M, et al. 2003b Cloning of adiponectin receptors that mediate antidiabetic metabolic effects. Nature 423 762-769. (https://doi.org/10.1038/nature01705)

Received in final form 13 June 2018

Accepted 2 July 2018

Accepted Preprint published online 3 July 2018 